Mirella Giannini, Dario Minervini, Ivano Scotti2*

\title{
The Reflexive Generation: Consumption, Crisis and Sustainability ${ }^{* *}$
}

The consumption analysis in the biographical narratives of young people makes it possible to outline the strategies enacted to deal with the 'late modernity' crisis scenario. Young people have incorporated the dimension of crisis - as incertitude and generalized risk - and they seem to perform reflexive consumption strategies closely linked, in some cases, to the sustainability issue, which emerges as a drive of the current consumption practices. However, consumption strategies differ for the individual endowment of social resources as well as biographical trajectories. This paper deals with this issue and the results of a qualitative research are reported.

Key words: consumption, crisis, sustainable strategies, young people (JEL: E20; E29; Q01)

\section{Introduction}

The sense of crisis - understood as uncertainty and generalized risk - is a structural experience in contemporary societies, that is incorporated in personal narratives (Giddens, 1991; Beck, 1999). Reflexivity, then, becomes a significant resource in the construction of coherent life paths, particularly the young generations, who experience unstable existential conditions (Leccardi, 2005; Leccardi and Ruspini, 2008).

The reflexive attitude fosters social changes, as it seems clear in the consumption sphere. Spaargaren (et al., 2012), for example, stresses how food consumption is changing in a sustainable way, due to crisis events located in people's private lives (illness, poisoning) and in wider social settings (food insecurity, pollution). Crises are sources of de-routinization of practices that push consumers to reflexively reconsider their lifestyle. However, the reflexive orientation is not equally distributed among subjects and the way to cope with the crisis can be widely different (Sweetman, 2003). In fact, some people face social incertitude through critical consumerism, while others experience it as socio-material downgrade. Bourdieu (1998) argued the relation between endowment of social resources, biographical trajectories

2 * Mirella Giannini, University of Naples "Federico II", Department of Social Sciences, Italy, email:migianni@unina.it

Dario Minervini, University of Naples "Federico II", Department of Social Sciences, Italy, dario.minervini@unina.it

Ivano Scotti, University of Naples "Federico II", Department of Social Sciences, Italy, email: ivano.scotti@unina.it

$1 * *$ Article received: July 31, 2015

Revised version accepted after double blind review: April 20, 2016

mrev, 28 (1) 2017, 1-3

DOI $10.5771 / 0935-9915-2017-1-80$ 
and consumption paths and his theoretical approach appears fruitful in the investigation of consumption in the age of crisis. Adopting a Bourdieusian perspective, our hypothesis is that younger generations have incorporated deep social changes that are noticeable in self-narratives about biographical trajectories and consumption choices.

In this respect, this paper aims to present findings from qualitative research on young people carried out in Naples (Italy). In particular, narrative interviews regarding their consumption patterns embedded into a specific context were conducted and analysed. The present paper is organized in four parts. The first one introduces the theoretical Bourdieusian framework, highlighting the key concepts used in our research (i.e. cultural capital, biographical trajectories, the habitus, etc.). Then, the Italian social context - the labour market and the consumption level - is briefly outlined, in particular referring to young Southern Italians. The description of the sample and the empirical findings are reported in the third part, where four consumption profiles are identified (two ordinary consumption styles, hedonistic and pragmatic, and two sustainable ones, selective and distinctive). Finally, the conclusion describes our contribution to the scientific debate and some theoretical insights.

\section{Consumption as a reflexive practice: a framework}

Sustainable consumption is a growing research field in social sciences. Spaargaren $(2003 ; 2013)$ stresses the reflexive subject's ability in establishing new consumption practices and lifestyles to face the crisis (the transformative capacity of agency). Shove (2003; 2013), on the other hand, highlights how links between elements of practice (meaning, skill, and device) can limit the subject's capacity to change consumption patterns (the illusion of agency). Both these scholars adopt a social practice theory perspective and little attention is paid to the "position" of actors in the social field (as well as the tension between actor and field). The point is relevant because it involves not only practices in itself, but concerns also the reflexivity of actors (Threadgold and Nilan, 2009; Sweetman, 2003). This is why Warde (2005) suggests a Bourdieusian framework to investigate the reflexivity in that symbolic and material practice - consumption - that constitutes "a way of life socially distinct" (Bourdieu 1979a in Santoro, 2001, p. XXI).

In Bourdieu's view, consumption has been thought as a symbolic element built in social relations whilst the agents are structuring social space through a set of consumption practices. The practices are performed strongly influenced by the individual and collective past events, and represented in a structure of interacted positions, competing in the hierarchical system where the powerful devices are often unrecognised. Practices reveal the cultural genesis of "taste" in one social position. In fact, the habitus, the types of economic, social and cultural capital, which get a meaning in social relations, contribute to defining specific tastes in classified social positions 
(Bourdieu and Wacquant, 1992). In particular, the cultural capital has three forms: the incorporated, the objective and the institutionalized one (Bourdieu, 1979b). The second and the third refer to the subjective cultural capital, but are the incorporated forms that take actively part in the classification mode of consumption and different ways of life. So, it is pointed out not only a way of life connected to particular living conditions, but also, and mainly, a process that finds in the habitus the unifying and generating principle of social classification. In addition to that, Bourdieu suggests how to locate the space of the way of life, in which one can identify consumption practices: for every configuration of capital, the habitus translates into a way of life "the bonds and the possibilities of that specifically classified and (relatively) homogeneous living condition" (Bourdieu, 1979a, pp. 217-218). As seen, it appears as soft determinism, since the habitus acts as the "spring", the impulse, the "unchosen principle of all choices" (Bourdieu, 2004, p. 97). As a consumer of specific goods in a specific way, the social agent plays in a field by investing his cultural capital, which is originated in the family, and formed by the capital achieved at the school (Bourdieu 2004, pp.5-6). Later on, tacit elements coming from the converted economic and social capital make up the individual trajectory, where the "alchemic" social link between unequal positions and perceptions of inequalities shows not only the explicit class indicators but also the additional social markers of effective exclusion, such as gender or territory (Bourdieu, 2004, p. 104, 177).

Therefore, the correlation between the symbolic and material consumption practice and social class or the position achieved in social classification, is the result of two (equal and opposite) effects: the imprinting effect, directly from the living conditions of the family, and the trajectory effect, that is "the experimented social rise and fall effect working on attitudes and opinions" (Bourdieu, 2004, p. 114). Through the experiences and perceptions so accumulated, the consumption practice translates into a pragmatic adaptation to the contingent pressures and needs in a specific field. Reflecting on the habitus as the outcome of experiences, and the consumption field as the relational structure of ways of life, the question is whether consumption practice simply replicates cultural world or if it can also change it. Furthermore, the issue of the possibilities of change can be approached in relation to this, given that they depend on the viewpoint in accordance with the specific habitus and living conditions.

The criticism brought to the Bourdieusian theory is that consumption practice is so strictly connected to the habitus and living conditions that the creativity and reflexivity of the social agent are annulled, and thus so is the possibility of cultural change. In other words, Bourdieu does not clearly carry out either the inventive ability, which de Certeau (1984) locates in thousands of daily practices performing the tactics of consumption, or the reflexivity, that he seems to keep out of the social agents (Lahire, 1998). In effect, as we know, Bourdieu agrees with Goffman when placing individual reactions to social and institutional needs into the context of living conditions. Right here in the individual reaction is the sens pratique, which is 
identified as guidance of choices and conducts of agents facing competitive viewpoints in the social structure. These daily competitions are less visible than the rhetorical, political ones, but just as effective in constructing the social world. Being tied to the present, daily choices are less reflexive than the choices made for possible future events (Bourdieu, 1997). So, in Bourdieu's view, daily choices and practices of consumption are less reflexive because they are rooted in acquired cultural patterns and linked to life styles in social classification by age, gender, and position.

In this divided world, where goods of consumption are converting into distinctive goods and symbols of distinction, the objective limits become the subjective "sense of one's place" (Bourdieu, 1979a, p. 473), the practical anticipation of the objective limits, already experienced by the individuals. Nevertheless, in the Bourdieusian framework, the social classification system is formally established and turns into an institution only when the sense of one's limit does not work. In this case of crisis, the power, at individual level, struggles to mobilize daily competitions, aimed at changing the categories of perception and evaluation of the social world. This is "one of the dimensions of the class struggle, often forgotten", that points out "how the incorporated limits become bonds that are to be shifted", says Bourdieu (1979a, pp.484-490).

As noted (Sassatelli, 2008), Bourdieu, almost similarly to Douglas e Isherwood, shows how consumptions have a communicative-relational and an aggregating function. Both of them spring from cultural practices of consumption evaluations on goods as judgements of value and on values, so that sharing a specific culture is the basis for social groupings as well as social distinction. In this view, the Bourdieusian emphasis of the social distinction compared to the cultural homologies in the groups seems to make difficult the exit from the original social position and not to allow for the changing of cultural practices of consumption. In effect, it is the relative nature of social distinction that opens up some hypotheses about changes in the communicative-relational dimensions of the consumer goods and in the new cultural practices of the responsible and sustainable consumption.

Therefore, recent studies on the new cultural practices of consumption have found that the Bourdieusian notion of social position allows the recognition of the role of class differences in mediating the future development of consumption (Paddock, 2015). Regarding reflexivity, which Bourdieu seems to underestimate in daily choices of consumption, analyses go beyond the positional and dispositional dimensions of social agents and focus on the interactive dimension to find the reflexivity into daily routine. From the perspective of social configuration, the relationship between habitus, cultural practices of consumption and reflexivity lets some intra-habitus tensions go out, due to the more general inconsistencies emerging in interactive-figurational structures (Mouzelis, 2007). A certain type of reflexivity emerges also when consumers are engaged in ethical and political questions, the so-called sustainable consumption. Consumers take individualized responsibility as individual- 
ized collective action, by combining individual with public interests and, in many cases, taking responsibility towards social injustices (Sassatelli, 2006; 2009; Micheletti and Stolle, 2007). In this case, consumption practices can be seen as judgements, which are distinctive but also antagonistic at the same time. It seems that the antagonistic culture of consumption converts into individualized responsibility, and not the other way around, i.e. the daily practice turns into collective actions.

\section{Crisis, consumption and youth in Italy}

The crisis, as job instability, seems so deeply incorporated in the young people that is possible to define them as the precarious generation (Giannini, 2016). Statistics on labour market and consumption can clearly detect the condition of youth and, as it will be shown, the precariousness represents a typical form of youth uncertainty, which affects lifestyle.

The Eurostat reports that in the Euro area (17 countries) the flexible-precarious employment, in the form of temporary and part-time jobs, has increased but it marks particularly younger generations. In 2000-2014 the temporary job rate (15-64 years old) increased by only 0.5 percentage points (pps), reaching $15 \%$ in 2014 , but for young people (15-29 aged), it went up by 3 pps, getting to $39 \%$ in the last year. Also, the part-time job rate has a similar trend, despite the difference between young people and the older population population being less noticeable (2 pps in 2014).

This data highlights that young generations experience unstable work and life paths that also worsened during the recent financial crisis. The European unemployment rate increased in 2008-2014 by 4 pps, and by 7 pps for young people. In the same period, in Italy, the youth unemployment rate doubled, the long-term unemployment tripled and underemployment of young people worsened (table 1). Not surprisingly, the risk of poverty or social exclusion is higher for them and a feeling of discouragement about the future is spreading out. The increase of NEETs (young people not in employment, education or training) confirms this negative trend.

Precariousness in youth seems also detectable in the consumption trends. If in pre financial crisis (2001-2008) the level of consumption grew less for young Italians $(+10 \%)$ than the average $(+14 \%)$, in 2008-2013 Italian household expenditure suffered a lager contraction $(-5 \%)$ compared to young people $(-3 \%)$. The incorporated crisis in the young generation helped to anticipate strategies in order to cope with financial difficulties as the different contractions in expenditure items shows (table 2). A higher contraction for some non-food items (i.e. furniture compared with leisure and culture) and a selective increase in food goods (fish and seafood, fruit and vegetables), suggests that young consumers are enacting a strategy to cope with the effects of the economic straits in their life. Therefore, statistics do not clarify if 
Table 1 - Statistics of the economic crisis in Italy and the Euro area in 2008-2014 for young people (15-29 years old)

\begin{tabular}{|c|c|c|c|c|}
\hline & \multicolumn{2}{|c|}{ Italy } & \multicolumn{2}{|c|}{$\begin{array}{c}\text { Euro area } \\
\text { (17 countries) }\end{array}$} \\
\hline & 2008 & 2014 & 2008 & 2014 \\
\hline Unemployment rate & 15.6 & 32.4 & 12.0 & 19.2 \\
\hline Long-term unemployment rate (at last 12 months) & 6.2 & 18.5 & 3.3 & 8.3 \\
\hline NEET rate & 19.3 & 26.2 & 13.2 & 15.7 \\
\hline People at risk of poverty or social exclusion (\%)* & 31.6 & 35.3 & 26.4 & 29.8 \\
\hline Percentage of temporary employees & 32.6 & 42.6 & 36.3 & 38.9 \\
\hline Percentage of part-time jobs & 17.0 & 24.6 & 19.9 & 24.8 \\
\hline Percentage of involuntary part-time employment & 62.2 & 81.6 & 30.0 & 36.7 \\
\hline
\end{tabular}

Source: Eurostat

* 16 -24 years old

Table 2 - Percentage change of some purchased items in Italy (2008-2013)

\begin{tabular}{|c|c|c|c|}
\hline & \multirow[b]{2}{*}{ Total } & \multicolumn{2}{|c|}{ Young people* } \\
\hline & & Italy & $\begin{array}{c}\text { Southern } \\
\text { Italy }\end{array}$ \\
\hline Food and beverages & -3.3 & 7.7 & 5.6 \\
\hline Bread and cereals & -7.0 & -7.4 & -12.3 \\
\hline Meat & -0.4 & 21.5 & 22.8 \\
\hline Fish and seafood & 0.8 & 28.0 & -3.0 \\
\hline Sugar, tea, cocoa and similar & -1.0 & 6.3 & -3.4 \\
\hline Beverages (wine, beer, water) & -3.1 & 4.7 & -7.7 \\
\hline Non-food items & -5.5 & -5.1 & -10.3 \\
\hline Clothing and footwear & -27.0 & -21.1 & -5.8 \\
\hline Furniture, appliances and household services & -20.1 & -39.7 & -35.7 \\
\hline Leisure and culture & -11.2 & -19.6 & -43.6 \\
\hline Others (travel, personal care products, etc.) & -11.0 & -6.2 & -22.3 \\
\hline Total & -5.1 & -3.3 & -7.1 \\
\hline
\end{tabular}

Source: ISTAT (Italian Statistical Institute)

* Singles and childless couples $\leq 35$

they are experiencing this strategy as a trend to a poorer lifestyle or, conversely, as a sober one.

However, in Southern Italy, young people suffer higher economic difficulties. In this less developed and rich area of Italy economic incertitude had larger negative effects. In 2014 the youth unemployment rate was 56\% (+14 pps compared to the National rate) and the expenditure of non-food goods fell by 10\% in 2008-2013 (noticeably in leisure and culture, personal care products, travel and tourism items). In short, in Southern Italy precarious life conditions are particularly exacerbated by the crisis. This led us to focusing on consumption strategies of young Southern Italians. Here, in fact, social dynamics of crisis appears to be more pronounced (Giannini, 2014). To deepen this issue, a qualitative research has taken place in Naples, 
the largest city in the South of Italy, because it is a representative case both for the living conditions and the lifestyles of young Southern Italians.

\section{Reflexive generation's strategies}

\subsection{Methodological notes}

The data analysed in this paper comes from a 34 narrative interviews (Schütze, 1992; Spanò, 2005) of young Neapolitan people (20-35 years old), part of a larger database ${ }^{3}$. A first set of interviews was collected from mid-2013 to mid-2014 selecting respondents from different social backgrounds (level of education, employment status, etc.). In this set only 7 respondents proved to be practising a certain type of alternative consumption (i.e. sustainable urban mobility, vegetarian diet, etc.). For the purpose of our research, ten more interviews were conducted with subjects who practised at least one form of alternative consumption at the beginning of 2015. In doing so, we collected a sample of 34 respondents divided in two numerically equal groups shared between those who practice one or more sustainable consumption and those who do not.

Specific issues (job experiences, consumption practices, etc.) were investigated using an abductive strategy of analysis (Abbott, 2004) ${ }^{4}$. The consistent dimensions coming from the theoretical framework - and shaping the research question - have been identified within the narratives, through the qualification and segmentation of transcriptions. In a recursive way, the analysis of data permitted the identification emerging pivotal issues, which set up the arguments developed in the biographical narratives.

The interviews were analysed in two steps. In the first one, through an interpretive grid (tab. 3), the respondents' different social backgrounds and their biographical trajectories were summed up. In this way it was possible to detect young consumers and their purchase styles, obtaining four different pictures of consumption strate-

3 Our interviews are part of a larger database collected for the research project PRIN 2010-2011 (Research projects of significant national interest) entitled Sustainable Everyday Practices in the Context of Crisis in Italy: Toward the Integration of Work, Consumption and Participation - funded by the Italian Ministry of Education, Universities and Research (MIUR) - coordinated by Prof. Laura Bovone of the Catholic University of Sacred Heart, Milan. The PRIN research team consists of seven Local Research Units (University of Milan, Bologna, Trieste, Rome, Naples and Molise) organized by a local coordinator. The Unit of Naples was coordinated by prof. Antonella Spanò. The local units of Milan and Naples drew up a similar set of questions on specific issues (job, consumption, the outlook of the future, etc.) to conduct biographical interviews in both of cities obtaining a wider sample of young people (20-35 years old) and 133 respondents (65 in Milan and 68 in Naples) who constitute the primary sample.

4 In this paper, we opt for a circular (abductive) relationship between theoretical framework (with related analytical dimensions) and empirical emerging issues (from narratives of people interviewed). By this "weak" inference (Ruiz, 2009), we have tried to explore (new) "explanatory hypothesis" (Pierce, 1931-1958) on consumption, sustainability and crisis. 
gies enacted by young people into two mains categories: the ordinary and the sustainable consumptions.

Table 3 - Interviews interpretive grid

\begin{tabular}{ll}
\hline 1) Basic data & 2) Personal biography \\
- age & - school career / educational level \\
- gender & - working path / job position \\
3) Birth family & 4) Consumption \\
- relatives' occupation status / path & - prevalent purchased items \\
- parents' education level & - consumption attitude / notion of "quality" \\
- receive /give financial parents help & - changes in purchasing \\
5) Opinion about the crisis & 6) Identity and the future \\
- who is more affected & - sense of belonging \\
- how the crisis is perceived & - self-description of lifestyle \\
- positive / negative aspects and solutions & - opinion about its personal future \\
\hline
\end{tabular}

Biographical information was coded to detect capitals endowment - in particular cultural and economic ones ${ }^{5}$ - organising data starting from the theoretical Bourdieusian frame. Then, the analysis of the biographical narratives allowed to pinpoint key issues related to consumption strategies, according to the abductive process mentioned above. In doing so, details emerging from the narratives were retraced and conceptualized - from specific/data to general/theoretical issues - around three main issues: motivation of consumption, way of narrating consumption, lifestyles exposed. Because of this methodological approach, the output of the analysis cannot be considered a proper typology of consumers, rather here emerging profiles of consumption are sketched on the basis of the circular relationship between theory and data (collected narratives).

Specific interview excerpts were chosen for descriptions of how young people account for their consumption patterns as well as on the emerging liaisons between personal endowment of social resources and reflexivity.

5 In the case of the cultural capital, educational qualification was the main variable considered and was coded as follows: high school degree (low), university degree (middle), master and $\mathrm{PhD}$ (high). Other cultural resources (specific skills and competencies) were considered in the classification, mainly to distinguish middle from high endowment. As mentioned in paragraph one, cultural capital in Bourdieusian terms is a very complex issue. Because of this, the coding has to be considered just a proxy to order information of people interviewed. With reference to economic capital, purchase independence and working conditions were combined as follows: parents dependent purchasing power/precarious working condition (low), intermittent autonomy in purchasing power/precarious working condition (middle), direct purchasing power/ quite stable working condition (high). Relations and social capital were not coded in a classification, but arguments in narrative interviews were considered in the construction of the consumption profiles. Level of income was not systematically recorded in the interviews, but the aforementioned combination of information seems to be an adequate proxy of economic capital consistent with the aims of the paper. 


\subsection{Youth's ordinary consumption between hedonism and pragmatism}

An in-depth analysis of biographical accounts allows us to reconstruct two profiles emerging from the sample of people who are not directly engaged in critical consumption practices. The methodology mentioned in the previous paragraphs led to retracing some similarities in their narratives. In particular people's arguments on their biographies were concentrated around the following issues: past and current experiences in the labour market, expenditure strategies and pattern of consumption, the relationship between the family of origin and the efforts to gain an independent economic life.

The first profile can be labelled as hedonistic ${ }^{6}$ and is related to those young people who described a discontinuous work life story, made of different fixed-term experiences, most of them starting during university years.

I'm a lawyer by choice but also because of the events. [...] Until 2008 I worked while I was studying at University. I did several jobs to be independent, so I was a babysitter, a dental assistant, a spinning instructor. I did everything and more to be able to treat myself and because I didn't want to ask for more from my parents, who assured all my needs (Gisella).

The argument about "treating herself" is common with interviewees and distinguishes between their actual needs and the ordinary consumption basket. Indeed, what emerges from the narratives is a sort of accessory side of consumption, which is mainly related to everyday quality of life. The satisfaction of cultural needs (books, theatre, and the cinema) is coherent with the idea of complementarity and strategies are enacted to optimize the opportunities. In the following quotation both essential and cultural needs are reported:

[...] giving up food is impossible [...] I check for special offers in supermarkets and, because we live in Naples, I can buy food in little shops that [...] are affordable. I can't give up cinema either [...] I have to go to the cinema sometimes because I love films and I try to check for free entrance" (Adele).

The hedonistic profile is very often characterized by a middle-high level of cultural capital; the young people in question hold a degree and sometimes are involved in (or are willing to attend) educational courses. Their parents hold quite the same level of education as well as cultural competences. In some particular cases this is narrated in terms of "reproduction" of tastes and consumption choices.

[...] my father holds an impressive vinyl collection because he is a jazz lover. [...] music is important to me also because when I was a child I used to play the piano, I did it for five years, I love music so much and I go to concerts [...] mainly jazz concerts, which are the most interesting for me" (Gisella).

6 Hedonistic, pragmatic, selective and distinctive are the labels here adopted to identify the profiles emerging from the analysis. All the labels are coherent with the theoretical framework, literally in the case of the distinctive. At the same time, it must be said that Campbell (1987) labelled "imaginative hedonism" the emotional pleasure gathered from the control of the meanings more than the materiality of objects, with reference to the modern consumption. 
The emphasis on cultural reproduction is absolutely less recurring than the discourses about the comparison between the economic status of parents and sons (or daughters). The main connection with the family of origin is expressed in terms of economic aid and support. To be more precise, when the interviewee accounts for their purchasing power, we can clearly notice that an indirect model based on a substantive economic dependence from the family of origin emerges.

[...] I finished my studies a while ago [...] nowadays I can't rely on a stable job and I can't support myself and I can't afford to pay the rent [...] I can't live my life in a proper independent way, without the support of my parents (Adele).

The biographies of the young hedonistic consumers show different variations of the same theme, i.e. the strategies to compose ordinary expenditure with personal treats, from the adaptive way to reach what is considered a decent level of cultural consumption, to a kind of "pedigree" argument to qualify cultural taste. At the same time it is possible to retrace a common idea about the future, that is based on long-term life projects and includes individual aims in particular for those who can rely on family resources (both in terms of cultural and economic capital). In other words, the subjects under discussion reflect on their recent past and on the present looking to the future, to a story that will have to be continued.

The second profile of those who do not explicate a critical/sustainable consumption in their narratives can be qualified as pragmatic. In these cases the main shared point is about their socio-economic difficulties in everyday life and some of them depict scenarios made of complicated life conditions related to exclusion and marginalization. Their work experiences are accounted as a fuzzy sequence of jobs, most of them informal and/or with a non-legit pay arrangement.

I didn't complete my nursing degree course and I started working. [...] my first experience was at a cash desk in a jewellery shop owned by my uncle. [...]. Then I was unemployed for five months and after that I started working in a bookmaker point [...] now I'm a model in discos. (Sergio).

These words show clearly how the chain from the education to the (poor) job path can be incoherent, based essentially on concrete and immediate opportunities to get money. In this specific case the subject's current job is connected with other activities (model, club promoter, etc.) allowing a satisfactory income at certain times. In other cases, the trajectories are associated to a sort of a trap of a continuous poor jobs sequence, within logic of pragmatic adaptation to contingencies. Economic resources, very often obtained on low wages, are directly spent on ordinary and necessary payments and needs (house rent, bills, food, petrol, etc.). This is the way to manage the everyday needs of a single mother, living with her mother, working in a fast-food restaurant:

I get 500 Euros per month [...] I had to stop my dental treatment because of lack of money. [...] My mother's health is getting worse [...]. I try to support her with half of my income when it's possible and I try to save 100 Euros for all contingencies. For example, this week I had to get my car repaired and my mother didn't have enough money to get that done. Unfortunately, we need the car for work purposes (Olimpia). 
The emphasis on the need of a car is related with travelling for work purposes, or in other cases with a traditional social meaning associated to the independency of male young adults. In these cases, the purchasing power can be depicted alternatively as direct and indirect, depending on the specific contingency and work conditions of them or of their parents. The biographical narratives collected report that, sometimes, economic resources from the family of origin are needed to support individual consumption while in other cases part of the income is allocated to help the family in their collective expenditure.

I help them (my parents, ed.), sometimes simply with a gift, not necessarily because they asked me for something $[\ldots]$ (Sergio).

When you don't have a job, you can't do anything from an economic point of view. My mother helps me if she can, otherwise I'll get it out of my system. Considering my jobs, which are weekend jobs or jobs on call... sometimes here, sometime there. I try to do things taking into account what is actually in my pockets (Saverio).

When life conditions seem less difficult, pleasure consumption is mentioned (from buying a smartphone to eating out). In any case, pragmatic consumers describe their needs, their strategies of expenditure and consumption without any reference to the sustainability issue. In this second profile life projects are based on a short-term or middle-term timing and these young people share a pragmatic awareness of the future. If planning seems to divide the two profiles, the impact of the financial crisis on life experiences and consumption behaviour is accounted in a very similar way. In fact, the crisis emerges first of all in terms of a big narrative, something like an epochal event, which involves all people and in particular those from the lower classes. The interviewees described their biographies from within the crisis and in very few cases the crisis is explicitly accounted as a direct or personal experience, also in terms of expenditure reduction or change in consumption patterns.

\subsection{Sustainable consumption: from selective to distinctive patterns of consumption}

The diffusion of alternative patterns of consumption inspired green and sustainable values to be considered a well-known and studied trend. As argued in the methodological part of the paper, a dedicated sample of critical consumers was meant to collect biographies of young people who practice sustainable consumption. Also in this case the analysis of the narratives allows us to identify two main emerging profiles, the first, closer to the idea of an individual and segmented qualification of consumption practices, the second inspired by a collective, cultural and political distinction from the mass behaviours. In these life stories the arguments emphasised by interviewees seem less structured along the dimension of the previous profiles (labour experiences, expenditure strategies, relation with the family of origin) and relevant similarities are shared both by those related to the selective profile and by those with the "distinction" one. 
The interview samples show significant convergences in terms of (middle) class origin and (middle-high) cultural capital. Almost all the subjects involved in the research hold a degree and in some cases also post-degree courses (from postgraduate to $\mathrm{PhD}$ courses). The narratives about their trajectories in the labour market seem to be very similar as well; in the majority of these cases, they recount discontinuous paths marked by multiple and diverse experiences. Job continuity is very limited, but this precarious condition in the labour market is very often culturally dependant, in other words these young subjects are able to spend their knowledge and skills in fixed-term, part-time or informal occupations. The following quotation effectively depicts this connection between cultural capital and job experiences:

[...] I'm an occasional worker. Since I got my degree and apart from three years of $\mathrm{PhD}$ grant, I had informal jobs or I got fixed-term contracts in the publishing industry, for this reason now I'm 32 and I've paid very few social security contributions. [...] I'm involved in different activities, also in research at University, in publishing jobs. I do private lessons [...] and I'm starting a postgraduate course in teaching Latin and Italian literature [...]. Sometimes I'm not paid properly but I hope that one day at least one of all those things I'm doing can turn into a permanent job (Antonello).

In the case of the distinctive profiles, the trajectory of incorporated cultural capital seems to be characterized by a discontinuous path linked to personal interests instead of a clear and linear educational project. More details about the relevance of cultural capital in the reflexive account of distinctive profiles about lifestyle will follow.

The last common trait of this "alternative" sample deals with consumption directly and in particular with food consumption that is the most argued point in the narratives and emerges as a key issue, which people pay attention to. But thereafter the commonalities stop here. Profile features emerge and diverge mainly in terms of judgement and motivation that are expressed on the basis of purchase behaviour.

The first argument that discriminates the selective profile from the "distinctive" one is related to the reasons why people express preferences towards alternative products, mainly those labelled as organic. Some interviewees have accounted for their choices basically for health reasons, expressing a very concrete and pragmatic judgement about some goods, and even if food is the pivotal good dimension, also other (few) goods are included in this selective "qualification" of consumption.

For me quality means healthy, [...] T-shirts, which are 5 or 10 Euros $[\ldots]$ are made of toxic materials, dangerous for the skin [...]. What I try to do also with the food is to eat healthy, good food and not junk food (Sandro).

The second profile is characterized more by a holistic approach and consumption practices are also interpreted in terms of coherence between different products purchased, basic needs and ethical choices.

I buy organic products, sometimes I pay more but I buy organic, not GMO, I boycott palm oil because I know they deforest and exploit Malaysia, causing the extinction of the local fauna, and also for the villages... in short for me it's not so easy to buy something! [...]. When I was younger I used to spend more money on clothes and shoes... See this pair of shoes? I have had this pair since teen 
years but they are very comfortable. [...] I don't want to buy anything that is made of animal skin because if you choose a certain eating habit you can't buy a leather bag. (Sandra)

The coherence of the basket composition is just one of the features of those that adopt a distinctive narrative. In some cases, the argument embraces a wider socioeconomic sphere, for instance for those who underline the relevance of the connection between production and consumption. The emphasis on this point, for example with detailed description of auto-productions experiences, is shared by subjects who are personally involved in organic food production or in environmental/political activism. The language of these young people becomes technical, articulated and based on specific knowledge and skill, from agriculture technicalities, to supply chain, logistics and marked analysis.

$[\ldots]$ growing vegetables with conventional chemicals means that you buy $[\ldots]$ a ton of fertilizer for

50 Euros per kilo [...] in the case of organic farming you buy compost that costs almost nothing but $[\ldots]$ productivity is lower $[\ldots]$ also labour costs have a high impact $[\ldots]$ there are several parameters that influence the final pricing of the products (Maria Grazia).

At the same time, everyday life practices related to consumption (eating, for example) are narrated in terms of organization and competences:

organic food deteriorates faster [...] in general you need life discipline that allows you [...] to organise a rational consumption of provisions also for more than one week (Maria Grazia).

A sort of expert narration emerges in the narrative of the distinctive profiles that put high emphasis also on their educational trajectory, driven by the search for the "real" interest and the knowledge that appears more coherent with their political dimension. The narratives, in some cases, link clearly the discourses about knowledge or skills with the involvement in a specific cause. In the next quotes, examples of reflexive arguments about discontinuity in education and lifestyle choices are outlined.

I graduated with a degree in Contemporary History. [...] during a summer school [...] we tested our writing skills and I was involved in a television program, designing a quiz on renewable energies. [...] My interests were not only in field of waste management but also in the [...] history of capitalism. [...] After a long time thinking about it I attended the Faculty of Literature [...] and I specialized in History $[\ldots]$ with a thesis on the ecology of time" (Matteo).

I went to the "Liceo Scientifico" high school [...] during the third year I quit [...] it was necessary to focus a little bit on my own interests [...]. Then, during the last years of the school, my Italian literature teacher invited me to attend the library [...] it happened that I chance upon fair trade, working and environmental sustainability [...] Since then I've paid attention to my ways of consumption (Maria Grazia).

It seems clear that the distinctive profile appears definitely informed and highly reflexive in the recounts of the way consumption is practised, while in the cases of qualification the fil rouge that connects lifestyle, ethical (and political) orientation and consumption appears weak and sometimes definitely not consistent. The next quotation is from an interviewee who appears to be very careful about meat consumption because of farming conditions and animals suffering, but when she speaks 
about her travelling habit something different and less involvement in the cause seems to emerge:

I love mixed journeys such as three weeks of culture, visiting temples [...] for example I was in Thailand [...] I rode an elephant, I hugged a tiger, it was crazy [...] and then if there is enough time for five days at the seaside, why not? (Valeria).

The overlapping between lifestyle and patterns of consumption emerge clearly when the biographical narratives deal with the theme of the current financial crisis. This issue seems the more effective one in discriminating the two profiles depicted so far. The distinction argument emerge in very explicit terms, sometimes in line with the self-production strategy that allows to be independent from the mass distribution system at least for some products, sometimes in a more radical strategy that means also a different idea of participation in the labour market. Critical consumption can be practised also in an age of crisis basically because the biography of these subjects was not directly affected by the 2008 financial collapse. It is quite clear that the (middle-high) social class origin supports these biographies of distinction from the mass lifestyle, both in terms of material and cultural resources. At the same time the discontinuity in job experiences, even when it is associated with a limited purchasing power, is accounted more as a choice than as what the labour market offers. To be and to act different from the mass' living path means also to have a different idea of the work, the working time, money (value) and a different order in expenditure priorities, that is to say, more in general, a different idea of the quality of life.

I do a lot of things but I don't think that without the crisis the situation would have been better than now [...]. If there had not been the crisis maybe I would have found a job in a company or I don't know where I could be doing things that I don't like or that I like less than what I'm doing now (Antonello).

[...] not that in the past my lifestyle was so expensive [...] I have a really old mobile phone, I don't have a smartphone [...] but I've never made big sacrifices, in short my lifestyle is quite the same as in the past, sometimes I have to give up buying books, and in that case it could be disappointing (Matteo).

We (my boyfriend and I, Ed.) have started this idea to reach autonomy in our jobs, jobs that we can bring with us and do at any time, in any place. [...] he is completing his course to get the tourist guide license $[\ldots]$ this is coherent with our project in the field of sustainable tourism [...] we have learned to synchronize our steps (Sandra).

Those who indicate a segmented qualification of their consumption patterns express a very different image of the crisis as well as of themselves in the post 2008 scenario. In this case difficulties and challenges are the ingredients of a picture that in some cases is depicted in depressive terms, not only in terms of material de-growth but also from a psychological point of view.

[...] then the crisis, in the world, with wars, the economic crisis and you think "OK, this doesn't affect me, I'm safe in my little world". Instead this is false because when you look around you can see 
that none of your friends is really satisfied, poor people starve to death [...] then you say "Holy $s^{* *} t$ we are going to hell!" (Valeria).

\section{Conclusion}

Through a Bourdieusian perspective, our study sought to investigate how young people narrate consumption in relation to uncertain existential life conditions. Although the consumption practices "in action" were not observed, the research has allowed us to investigate the relationship between the narratives of consumption and the respondents' habitus. Findings of our research are summarized in the synoptic tables $4 \mathrm{a}$ and $4 \mathrm{~b}$ where the profiles and features detected are reported.

On the one hand, the results seem to highlight how the habitus enacts a specific disposition in consumption practices and in lifestyle as well. On the other hand, the habitus emerges as the organizing principle of a shared social classification. The profile comparison make this point clear. The decreasing purchasing power is narrated by pragmatic profiles as a consequence of the disadvantageous labour market conditions, which is coped with through a flexible adaptation in a sequence of poor jobs. They share with parents a low educational attainment, the same social conditions and, sometimes, life trajectory. Conversely, in the case of the hedonistic consumers, the purchase limitations are described in relation with a strategy meant to optimize economic opportunities in reaching a "decent level of quality of life", that includes the satisfaction of cultural and leisure needs (travels, books, etc.). In this case the middle-high level of cultural capital detected seems to influence preferences and 'taste' that, of course, are more than an individual affair. In these narratives, however, the issue of sustainability does not emerge as a relevant theme.

\section{Synoptic Table 4a - Features of "Ordinary" Consumption Profiles}

\begin{tabular}{|l|r|r|r|}
\hline \multirow{2}{*}{ Profiles } & \multicolumn{3}{|c|}{ Features } \\
\cline { 2 - 4 } & Job experience & Expenditure emphasis & Family relationship \\
\hline Hedonistic & Qualified & Leisure needs & Dependence \\
\hline Pragmatic & Low-qualified & Basic needs & Integration \\
\hline
\end{tabular}

Synoptic Table 4b - Features of "Sustainable" Consumption Profiles

\begin{tabular}{|l|r|r|r|}
\hline \multirow{2}{*}{ Profiles } & \multicolumn{3}{|c|}{ Features } \\
\cline { 2 - 4 } & Approach to consumption & Narratives & Lifestyle \\
\hline Selective & Quality esteem & $\begin{array}{r}\text { Mundane } \\
\text { (ref. to leisure) }\end{array}$ & $\begin{array}{r}\text { Common } \\
\text { (with the mass) }\end{array}$ \\
\hline Distinctive & Ethical disposition & $\begin{array}{r}\text { Expert } \\
\text { (ref. to politics) }\end{array}$ & $\begin{array}{r}\text { Detached } \\
\text { (from the mass) }\end{array}$ \\
\hline
\end{tabular}


The other two profiles are quite similar because of the educational level (middlehigh qualification), job experiences (intermittent but well qualified) and the social origins (mainly from middle-high class), as well as because of the sustainable consumptions emphasis in their narratives. Nevertheless, sustainable consumption is more related to the personal well-being for those detected with the selective profile. The lifestyle is accounted as "ordinary" in the majority of cases. On the contrary, distinctive consumers seem to hire cultural capital in signifying sustainable consumption practices through ethical commitments. Their judgement on how and why consumption is made appears deeply embedded in a life trajectory. Here personal engagement in wider socio-political issues (i.e. the animal rights, the downshifting, etc.) seems to play a relevant role in defining consumption judgement and in driving purchase choices.

In short, findings seem to support the theoretical assumption that consumption strategies emerge from two intertwined socio-cultural dynamics: the social origins and the everyday life personal experiences (Bourdieu, 2004). Consumers enact (and reflect about) strategies closely linked to the environmental sustainability with the aim to cope with crisis in wider terms. Indeed, critical consumption is accounted as "collective individualized action" (Micheletti, 2003). At the same time, consumption is strictly tied with the narration about the precariousness sense of life descending (also) from the inconsistency between the habitus of young people and that one of their parents.

In theoretical terms, an intra-habitus contradiction (Mouzelis, 2007) stands out and opens a "space of possibilities" (Bourdieu, 1979) for social agents, which enacts a specific form of reflexivity. The age of crisis obliges, as an outside necessity, to develop a "reflexive habitus" (Sweetman, 2003). The intra-habitus contradiction, instead, lies inside of social agents and implies a reflection on ethical issues. This last tension is a conflict between contradictory cultural dispositions, incorporated by social agents in life experiences, which imply a choice among alternative values. This seems the case of the subjective reflection related to environmental and consumerist culture. The kind of ethical questions (and answers) are also differentiated by the endowment of social resources of social actors. Then, not surprisingly, the alternative profiles detected are peculiar of middle-high classes but, social agents can adopt an antagonist or distinctive strategy as an individualized ethical answer to the crisis.

\section{References}

Abbott, A. (2004). Methods of Discovery: Heuristics for the Social Sciences. New York: W. W. Norton \& Company.

Beck, U. (1999). World Risk Society. Cambridge: Polity Press.

Bourdieu P. (1979b). Les trois états du capital culturel. Actes de la recherche en sciences sociales, 30, 3-6.

Bourdieu, P. (1979a). La distinction. Critique sociale du jugement. Paris: Minuit. 
Bourdieu, P. (1997). Méditations pascaliennes. Paris: Seuil.

Bourdieu, P. (1998). Practical reason: on the theory of action. Redwood: Stanford University Press.

Bourdieu, P. (2004). Esquisse pour une auto-analyse. Paris: Raison d'agir.

Bourdieu, P., \& Wacquant, L. (1992). Réponses. Pour une anthropologie réflexive. Paris: Seuil.

de Certau, M. (1984). The Practice of Everyday Life. Berkeley: University of California Press.

Giannini, M. (2014). Las trampas de los trabajos flexibles. In: A. Giglia \& A. Miranda, A. (curation). Precariedad urbana y lazos sociales. Una mirada comparativa entre Mexico y Italia (pp. 217-244). Ciudad de México: Juan Pablos \& UAMI.

Giannini, M. (2016). Epistemologia della condizione precaria: oltre il declino del lavoro salariato. Quaderni di teoria sociale, 2, 97-124.

Lahire, B. (1998). L'homme pluriel: les ressorts de l'action. Nathan: Pluriel.

Leccardi C., \& Ruspini E. (2008). A New Youth? Young People Generations and Family Life. Aldershot: Ashgate.

Leccardi, C. (2005). Facing Uncertainty. Temporality and Biographies in the New Century. Young, 13(2): 123-146.

Micheletti, M. (2003). Political Virtue and Shopping: Individuals, Consumerism, and Collective Action. London: Palgrave Macmillan.

Micheletti, M., \& Stolle, D. (2007). Mobilizing Consumers to Take Responsibility for Global Social Justice. The Annals of the American Academy of Political and Social Science, 611(1), 157-175.

Mouzelis, N. (2007). Habitus and Reflexivity: Restructuring Bourdieu's Theory of Practice. Sociological Research Online, 12(6), doi:10.5153/sro.1449.

Paddock, J. (2015). Positioning Food Cultures: 'Alternative' Food as Distinctive Consumer Practice. Sociology, doi:10.1177/0038038515585474.

Peirce, C. S. (1931-1958). Collected Papers of Charles Sanders Peirce. Cambridge: Harvard University Press.

Ruiz, J. (2009). Sociological Discourse Analysis: Methods and Logic. Forum Qualitative Sozialforschung / Forum: Qualitative Social Research, 10(2), Art. 26, http://nbn-resolving.de/ urn:nbn:de:0114-fqs0902263.

Santoro, M. (2001), Presentazione. In P. Bourdieu. La distinzione. Critica sociale del gusto. Bologna: il Mulino. p. XXI.

Sassatelli, R. (2006). Virtue, Responsibility and Consumer Choice. Framing Critical Consumerism. In J. Brewer \& F. Trentmann (eds.). Consuming Cultures. Global Perspectives (219-250). Oxford: Berg, Oxford.

Sassatelli, R. (2008). Consumo. Appropriazione creativa, mercificazione, circuito culturale delle merci. In C. Demaria \& S. Nergaard (a cura di). Studi culturali. Temi e prospettive a confronto (223-254). Milano: McGraw-Hill.

Sassatelli, R. (2009). Consumership. (De)costruire il consumatore-cittadino. Partecipazione e conflitto, 3, 51-58.

Schütze, F. (1992). Pressure and guilt: war experiences of a young German soldier and their biographical implication (part 1). International Sociology, 2, 187-208. 
Shove, E. (2003). Comfort, Cleanliness and Convenience: The Social Organization of Normality, Oxford: Berg.

Shove, E., \& Spurling N. (eds) (2013). Sustainable Practices: Social Theory and Climate Change. London: Routledge.

Spaargaren, G. (2003). Sustainable Consumption: A Theoretical and Environmental Policy Perspective. Society and Natural Resouces, 16(8): 678-701.

Spaargaren, G. (2013). The Ecological Modernization of Social Practices at the ConsumptionJunction. Theoretical Reflections Underpinning Empirical Research on Sustainable Consumption Culture della Sostenibilità, IV(2), 31-65.

Spaargaren, G., Oosterveer, P., \& Loeber, A. (2012). Food Practices in Transition. Changing Food Consumption, Retail and Production in the Age of Reflexive Modernity. New York: Routledge.

Spanò, A. (2005). Approccio biografico e identità in transizione. La critica sociologica, 155, 67-82.

Sweetman, P. (2003). Twenty-first century dis-ease? Habitual reflexivity or the reflexive habitus. The Sociological Review, 51(4): 528-549.

Threadgold, S., \& Nilan, P. (2009). Reflexivity of Contemporary Youth, Risk and Cutural Capital. Current Sociology, 57(1): 47-68.

Warde, A. (2005). Consumption and Theories of Practice, Journal of Consumer Culture, 5(2): 131-153. 